\title{
Texture, microstructure and consumer preference of mango bars jellified with gellan gum
}

\author{
Florina Danalache a, b, Sara Beirão-da-Costa ${ }^{\text { }}$, Paulina Mata ${ }^{\text {a }}$, Vítor D. Alves ${ }^{\text {b }}$, \\ Margarida Moldão-Martins ${ }^{\mathrm{b}, \text { * }}$ \\ ${ }^{a}$ REQUIMTE/CQFB Departamento de Química, Faculdade de Ciencias e Tecnologia, Universidade Nova de Lisboa, Quinta da Torre, 2829-516, Caparica, \\ Portugal \\ ${ }^{\mathrm{b}}$ LEAF - Linking, Environement, Agriculture and Food, Instituto Superior de Agronomia, Universidade de Lisboa, Tapada da Ajuda, 1349-017, Portugal \\ c PROSENSE, Lda - Soluções em Análise Física \& Sensorial, INOVISA, Universidade de Lisboa, Tapada da Ajuda, 1349-017, Portugal
}

\section{A R T I C L E I N F O}

\section{Article history:}

Received 13 August 2014

Received in revised form

14 November 2014

Accepted 16 December 2014

Available online 24 December 2014

\section{Keywords:}

Mango jellified bars

Gellan gum

Texture

Sensory analysis

Microstructure

\begin{abstract}
A B S T R A C T
Studies for the development of a novel convenient fruit product based on mango puree and gellan gum were carried out. Two gellan types (low acyl-L and high acyl-H) used in specific L/H ratios (75/25, 50/50, $25 / 75$ ) for an overall concentration of $1 \mathrm{~g}$ of gellan/100 $\mathrm{g}$ of puree were tested, in order to design different mango bars. The influence of the $\mathrm{L} / \mathrm{H}$ gellan ratio on their texture properties (TPA and SR tests), microstructure (Cryo-Scanning Electron Microscopy) and texture sensory acceptance (PreferenceRanking test) was studied. The results obtained enabled to separate the bars in two groups: the ones showing greater hardness and brittleness (only L gellan, and $\mathrm{L} / \mathrm{H}$ at the ratios of $75 / 25$ and 50/50); and those presenting a softer structure with higher cohesiveness and springiness values $(\mathrm{L} / \mathrm{H}$ of $25 / 75$ and only $\mathrm{H}$ gellan). The microstructure of mango bars was consistent with the texture results. Those presenting higher hardness have shown a microstructure composed of a denser biopolymer network with lower pore size; while for softer bars with higher springiness, larger pores and thin strings were observed. From the Preference-Ranking test, the most appreciated mango bar in terms of texture was the one prepared with a $\mathrm{L} / \mathrm{H}$ ratio of $25 / 75$.
\end{abstract}

Published by Elsevier Ltd.

\section{Introduction}

Tropical fruit production, trade and consumption have increased significantly, due to their attractive sensory properties and growing recognition of their nutritional and therapeutic properties (Bicas et al., 2011). Gorinstein et al., (1999), compared 8 tropical fruits and concluded that ripe mango had the highest gallic acid content and total polyphenolics, which make this fruit valuable for health maintenance, particularly protection against coronary heart disease and cancer. Its good texture, flavour and high amounts of antioxidants, mainly $\beta$-carotene, phenolic compounds, vitamin $C$ and minerals (Schieber, Ullrich, \& Carle, 2000), promoted mango as a suitable raw material for various applications in functional food production. One of its most processed forms is as pulp, which is further used for manufacturing final products such as fruit drinks,

\footnotetext{
* Corresponding author. Tel.: +351 21 3653547; fax: +351 213653195 .

E-mail address: mmoldao@isa.utl.pt (M. Moldão-Martins).
}

powders, jams, purees and dehydrated slices (Djantou, Mbofung, Scher, Phambu, \& Morael, 2011; Ledeker, Suwonsichon, Chamber, \& Adhikari, 2014; Liu, Li, Wang, Bi, \& Liao, 2014; Sogi, Siddiq, \& Dolan, 2015; Sriwimon \& Boonsupthip, 2011).

Gellan gum, approved for use in food industry (Morris, Nishinari, \& Rinaudo, 2012) was chosen in this work as texturizer. This hydrocolloid is used not only as a gelling agent; but also as stabilizing, film-forming, thickening and flavour-releasing agent (Bajaj \& Singhal, 2007). Gellan gum has been used in a wide variety of food products including confectionary, jams, jellies, pie fillings, puddings, ice cream and yogurt (Noda et al., 2008; Lau, Tang, \& Paulson, 2000).

This extracellular bacterial polysaccharide is secreted by Sphingomonas elodea (ATCC 31461), previously referred to as Pseudomonas elodea. Its linear structure is based on the tetrasaccharide repeating unit $\rightarrow 4$ )-L-rhamnopyranosyl-(a-1 $\rightarrow 3$ )-Dglucopyranosyl-( $\beta$ - $1 \rightarrow 4)$-D-glucoronopyranosyl-( $\beta$ - $1 \rightarrow 4)$-D-glucopyranosyl- $(\beta-1 \rightarrow$. In its native form (high acyl $-H)$, two acyl substituents - acetate and glycerate - are present. Both substituents are located on the same glucose residue, with one glycerate per 
repeat unit and one acetate per every two repeat units. Both substituents may be removed by treatment of the fermentation broth with hot alkali, being the resulting deacylated polymer known as low acyl gellan gum - L (García, Alfaro, Calero, \& Muňoz, 2011; Noda et al., 2008; Yamamoto \& Cunha, 2007). The acyl groups have a profound influence on gel characteristics. The high acyl gellan produces soft and elastic gels whereas the low acyl yields hard and brittle gels (Ortega \& Sanderson, 1994; Philips \& Williams, 2009). Gels formed by gellan gum are characterised by their sparkling clarity, good flavour release and fast setting behaviour (Sworn, 2000).

Beyond the type of gellan other factors have influence on the texture of the gels formed, such as, gum concentration, $\mathrm{pH}$, temperature, type of cations and their concentration, and sugar content. The advantages of using gellan gum for food product development rely on interactions with other polysaccharides and between the two gellan types, which allows the production of a wide range of textures (Chandrasekaran \& Radha, 1995). Biopolymer blends may provide structures with superior properties than a system composed by only one type of polymer (Banerjee \& Bhattacharya, 2011; Mao, Tang, \& Swanson, 2000).

Fruit purees/juices along with gelling agents can be used in the development of novel food products with a variety of textures (Mancini \& McHugh, 2000). Banerjee, Ravi, and Bhattacharya (2013), developed gels based on gellan gum and agar with carrot juice. In addition, gels based on pineapple juice with different concentrations of gellan gum were studied by Saha and Bhattacharya (2010). Moreover, Sworn and Kasapis (1999) and Bayarri, Costell, and Duran (2002) studied the effect of sugar, a common additive in many food formulations, on gellan gels properties. The obtained food gels have been characterized on the basis of their texture attributes - one of the most important characteristics which may affect the consumer acceptance.

Texture attributes are used to monitor and control product quality and acceptability (Chen \& Opara, 2013). In order to have a better understanding about the texture of the food gels, a characterization from a rheological point of view by employing small and large deformation tests (Zhang, Daubert, \& Foegeding, 2005) might be suitable. Stress Relaxation tests (SR) involving smalldeformation, allow defining parameters such as relaxation time, elastic moduli and viscosity. Studies have been performed regarding stress-relaxation tests of food materials in order to investigate the effect of ingredients and processing conditions. Yildiz et al. (2013) analysed wheat starch/dietary fibre systems where different models were used to describe stress-relaxation behaviour, such as the Maxwell and Peleg models. Mancini, Moresi, and Rancini (1999) were able to describe the viscoelastic behaviour of several alginate gels, differing in the effective alginate concentration, by means of a generalized Maxwell model consisting of five elements. Furthermore, large-deformation tests such as Texture Profile Analysis (TPA) partially simulate biting and chewing actions inside the mouth, are of practical use for product development and evaluation of consumer acceptance. From TPA analysis, hardness, cohesiveness and springiness are some of the most important parameters that should be assessed during food products development.

The aim of the present work is focused on the study of the relationship between the texture properties, microstructure and sensory acceptance of mango bars, as convenient products presenting sensory attributes identical to the fresh fruit. The bars were produced using different $\mathrm{L} / \mathrm{H}$ ratios, with the same overall concentration ( $1 \mathrm{~g}$ of gellan/100 $\mathrm{g}$ of puree), enabling the design of a wide range of texture properties. TPA, SR tests, Cryo-SEM analysis and sensory evaluation by Preference Ranking method were performed in order to select the formulation with the highest acceptability for the final mango bar product.

\section{Materials and methods}

\subsection{Materials}

Two types of commercial gellan gum were supplied by CP Kelco, Wilmington, USA: low-acyl gellan gum (Kelcogel ${ }^{\mathbb{B}} \mathrm{F}$ ) and high-acyl gellan gum (Kelcogel ${ }^{\mathbb{B}}$ LT). Mature mangoes (Mangifera indica L. cv. Palmer) were purchased in a local supermarket and stored at $5 \pm 1{ }^{\circ} \mathrm{C}$ until processing (within $24 \mathrm{~h}$ ). Fruits were selected based on the same ripening stage (soft texture and TSS value around $18^{\circ}$ Brix - best stage for consuming), uniform size and absence of any physical injuries, were selected.

\subsection{Methods}

\subsubsection{Preparation of mango bars}

The fruit was washed under running water, and manually peeled with a knife, cut into small pieces, and pureed in a food blender Thermomix TM-31 at $134 \times \mathrm{g}$ for $4 \mathrm{~min}$ at room temperature. Afterwards, the obtained puree was transferred into an $80 \mathrm{~mL}$ glass beaker immersed into a $1 \mathrm{~L}$ hot water bath. The goal was to improve the gellan dispersion avoiding the heat burn of the mango puree. The water bath temperature was increased in order to heat the mango puree up to a temperature of $88 \pm 2{ }^{\circ} \mathrm{C}$ followed by the addition of gellan powder and stirring at a rotation speed of $1640 \times g$ with a four bladed impeller. MP (mango puree)/L/H samples with an overall gellan concentration of $1 \mathrm{~g}$ of gellan/100 $\mathrm{g}$ of puree, varying the $\mathrm{L} / \mathrm{H}$ ratio (MP-L, MP-L/H75/25, MP-L/H50/50, MP-L/H25/75, MP-H), were prepared. The MP/gellan mixtures were placed into rectangular silicon moulds $(\mathrm{W} \times \mathrm{H} \times \mathrm{L}=27 \times 10 \times 50$ $\mathrm{mm}$ ) and allowed to set at room temperature $\left(22 \pm 2{ }^{\circ} \mathrm{C}\right)$ (Fig. 1$)$. Afterwards, the samples were stored at $5{ }^{\circ} \mathrm{C}$ for $30 \mathrm{~min}$ before being analysed.

The detailed procedure for the selection of gellan concentration (1 $\mathrm{g}$ of gellan/100 $\mathrm{g}$ of puree) is described in a recent work (Danalache, Mata, Moldão-Martins, \& Alves, 2015). The short time of stirring (30 s) at $88 \pm 2{ }^{\circ} \mathrm{C}$ was chosen in order to promote the dispersion of the gellan powder, as well as enzyme deactivation (polygalacturonase, - responsible for texture softening and polypheniloxidase for browning) with minimal deterioration of the sensory properties of the fruit.

\subsubsection{Stress-relaxation tests}

SR tests were carried out with a Texture Analyzer model TA.TX Plus (Stable Micro Systems, Ltd., UK) equipped with a $50 \mathrm{~N}$ load cell, using an aluminium flat plate with a diameter of $60 \mathrm{~mm}$. A thin

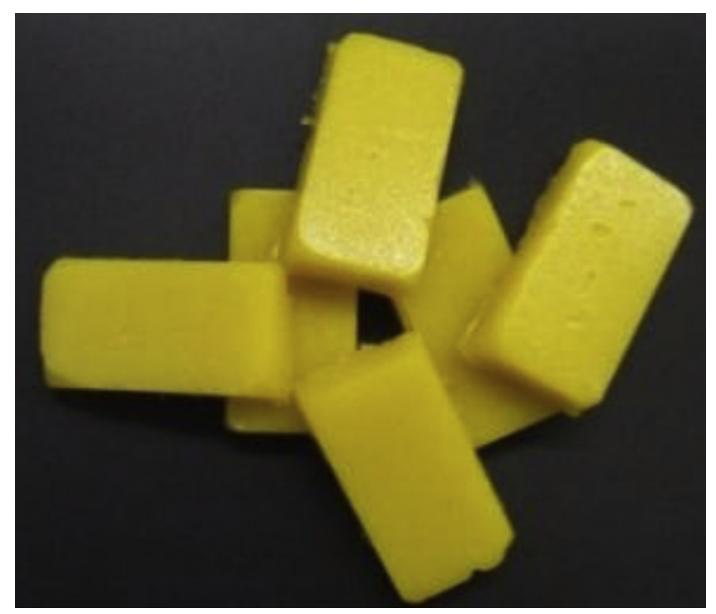

Fig. 1. Mango bars used in sensory analysis and texture measurements. 
layer of paraffin oil was applied between the equipment surfaces in order to avoid friction. Samples with dimensions of: $\mathrm{W} \times \mathrm{H} \times \mathrm{L}=27 \times 10 \times 25 \mathrm{~mm}$ were transferred to the equipment. The mango bars were compressed up to $10 \%$ deformation of the initial height using a cross-head speed of $0.5 \mathrm{~mm} \mathrm{~s}^{-1}$ and allowed to relax for $1200 \mathrm{~s}$, while stress decay was monitored over time. Tests were performed in triplicate.

There are several mathematical models that can describe the behaviour of viscoelastic food products; nevertheless the Maxwell and Peleg models are more often used to describe the behaviour of the gels and food systems (Andrés, Zaritzky, \& Califano, 2008; Bellido \& Hatcher, 2009). The simplified Maxwell model involves two elements representing different behaviours: an ideal elastic element represented as a spring (E), and an ideal viscous element, represented by a dashpot $(\eta)$ (Campus et al., 2010). Some food products do not follow the simplified Maxwell model, and thus, the description of their behaviour requires more complex models as the generalized Maxwell model, which consists of an infinite number of simplified Maxwell models in parallel over a spring (Eq. (1)).

$\sigma(t)=\varepsilon_{0}\left(E_{1} \exp \left(-\frac{t}{\lambda_{1}}\right)+E_{2} \exp \left(-\frac{t}{\lambda_{2}}\right)+\ldots+E_{e}\right)$

where $\sigma(t)$ is the decreasing stress over time, $\varepsilon_{0}$ is the initial constant strain, $E_{i}$ are the elastic moduli of the ideal elastic body, $t$ is the compression holding time, $\lambda_{\mathrm{i}}$ are the relaxation times that are equivalent to $i / E_{i}$ and $\mathrm{E}_{\mathrm{e}}$ is the equilibrium elastic modulus.

The SR data can also be described using Peleg model (Kaletunc, Normand, Nussinovitch, \& Peleg, 1991).

$\sigma(t)=\sigma_{e}+\sigma_{0}\left(\frac{k_{1} / k_{2}}{k_{1}+k_{2} \cdot t}\right)$

where, $\sigma_{\mathrm{e}}$ is the residual stress, $\sigma_{0}$ is the initial relaxation stress, and $\mathrm{k}_{1}$ and $\mathrm{k}_{2}$ are the empirical constants. The constant $\mathrm{k}_{1}$ is a measure of how easy the material deforms. High values of $\mathrm{k}_{1}$ suggest a hard material, which will dissipate less energy, and thus requiring more force to be compressed. The constant $\mathrm{k}_{2}$ represents the degree of relaxation of the material.

The models were fitted to the experimental results and the goodness of the fits was evaluated using the correlation coefficient $\left(\mathrm{R}^{2}\right)$ and the Absolute Average Deviation (AAD) calculated by Eq. (3).

$A A D=\left\{\left[\sum_{i=1}^{n}\left(\frac{\left|y_{i, \exp }-y_{i, \text { calc }}\right|}{y_{i, \exp }}\right) / n\right]\right\} \times 100$

where $y_{i, \exp }$ and $y_{i, c a l c}$ are the experimental and calculated responses, respectively, and $\mathrm{n}$ is the number of experimental runs (Rodrígues-Sandoval, Fernandez-Quintero, \& Cuvelier, 2009).

\subsubsection{Texture Profile Analysis}

In order to mimic the human biting action, the samples were carried out with a Texture Analyzer model TA.TX Plus (Stable Micro Systems, Ltd., UK) equipped with a $50 \mathrm{~N}$ load cell, using a method based on the one used by Mandala, Palogou, and Kostaropoulos (2007). A double compression cycle test was performed up to $60 \%$ strain of the original height using an aluminium plunger with $60 \mathrm{~mm}$ diameter, with a time of $5 \mathrm{~s}$ between the two compression cycles. A thin layer of paraffin oil was applied between the plates and the testing sample in order to avoid friction. Hardness (N) was defined as the maximum force during the first compression cycle and springiness was measured as the ratio of the second and first compression distances until maximum forces. Cohesiveness is the ratio of the positive force area during the second cycle to that of the first cycle of compression. Tests were performed in triplicate at room temperature $\left(20 \pm 2{ }^{\circ} \mathrm{C}\right)$.

\subsubsection{Cryo-SEM}

The method used was based on the one applied by Sriamornsak Thirawong, Cheewatanakornkool, Burapapadh, and Sae-Ngow (2008). Cryo-SEM of thin slices of mango bars was performed with an EOL JSM $6301 \mathrm{~F} /$ Field Emission, Oxford UK instrument equipped with a cryo sample preparation system (Gatan Alto 2500). The samples were immersed into liquid nitrogen at $-210{ }^{\circ} \mathrm{C}$ for $15 \mathrm{~s}$ and freeze fractured to expose fresh surfaces for sublimation, then covered with a $10 \mathrm{~nm}$ layer of gold. The gold coated samples were observed and photographed with an accelerating voltage of $15 \mathrm{kV}$ and at temperatures below $-135{ }^{\circ} \mathrm{C}$ with a magnification in the range of $5000-40000 \times$.

\subsubsection{Sensory analysis}

Sensory analysis was performed in order to identify the mango bar with the highest texture acceptability. A Preference-Ranking test was performed (ISO 8587:2006) whereby each panellist was asked to evaluate the samples by preference, considering one single sensory attribute - the overall texture. This option was justified due to different textures among the mango bars, while the other attributes were considered relatively similar. Texture will be determinant in selecting the mango bars, taking into account that this attribute is one of the most important in developing food products similar to bars. The sensory evaluation of the mango bars was carried out in a sensory room with 6 analysis boxes, in accordance with ISO 8589:2006. The 63 panellists ( 14 males and 49 females), aged between 20 and 65 years old, were students or staff members of Instituto Superior de Agronomia (Lisbon, Portugal) identified as regular consumers of mango fruit. The five different mango bars were presented at room temperature $\left(20-22^{\circ} \mathrm{C}\right)$ in random order and labelled with randomly-generated three-digit codes.

The score sheets required the judges to rank their five samples in the order of preference: (1) the least; (2) slightly; (3) moderately; (4) neither liked nor disliked and (5) the most preferred texture (Meilgaard, Civille, \& Carr, 1999). Additionally, the panellists were asked to justify their choices. Friedman test (significance level $\mathrm{p} \leq 0.05$ ), was used to determine whether each sample was significantly preferred over the others.

\subsubsection{Statistical analysis}

The software Scientist was used to fit the SR models to the experimental data. One-way variance analysis (ANOVA) was performed to evaluate the statistical difference between estimated parameters of the samples. PCA was carried out to study the multivariate results regarding the bars physical characteristics using the software STATISTICA version 6.0 (2001) (StatSoft Inc., Tulsa, OK, USA).

\section{Results and discussions}

\subsection{Stress relaxation properties of mango bars}

The SR behaviour of mango bars jellified with $\mathrm{L}$ and $\mathrm{H}$ gellan at different ratios was studied, imposing an initial strain of $10 \%$, and the stress-time curves are presented in Fig. 2. A maximum stress was observed for all cases, obtained upon the application of the constant deformation. It was followed by a typical behaviour of viscoelastic materials, where the stress necessary for the maintenance of the deformation decreased with time (Pereira et al., 2013; Roopa \& Bhattacharya, 2014; Tang, Tung, \& Zeng, 1998). The highest stress values were observed for MP-L sample. As the L gellan content decreased, lower values of the stress were observed over the 


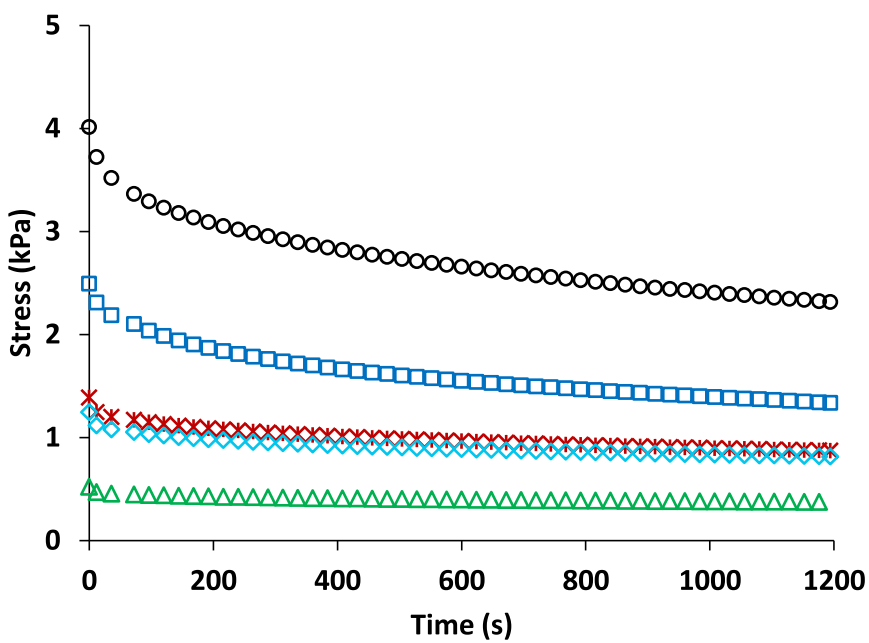

Fig. 2. SR curves of $M P / L / H$ samples for $10 \%$ strain and $0.5 \mathrm{~mm} \mathrm{~s}^{-1}$ cross-head speed;

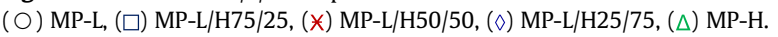

time range studied, with a good discrimination between the samples. The formulation MP-H registered a considerable lower initial stress $\left(\sigma_{0}=0.5 \mathrm{kPa}\right)$. The reason for this behaviour is due to different properties of $\mathrm{H}$ gellan which produces soft, elastic and non-brittle gels. These characteristics tend to be present in the mango puree/H gellan matrix, and when it is subjected to a constant strain, very short relaxation times are observed, with an almost constant stress-time curve during the entire test. These results indicate that $\mathrm{H}$ gellan imparts a lower structural firmness to the bars than L gellan. Nevertheless, MP-H sample is a viscoelastic material, as observed in previous rheological measurements (Danalache et al., 2015). The mechanical spectrum of this sample has shown values of the elastic modulus $\left(G^{\prime}\right)$ greater than the viscous modulus $\left(G^{\prime \prime}\right)$ at all values of frequency.

The relaxation curves were fitted by three models: the Peleg's model, the simplified Maxwell model and generalized Maxwell model (with two Maxwell elements in parallel with a pure elastic element). A typical relaxation curve (formulation MP-L) fitted with the three models is presented in Fig. 3. The generalized Maxwell model with two elements was the one that best described the experimental data for all bars formulations, with a $\mathrm{R}^{2}$ of 0.999 and $A A D$ values in the range of $0.06-0.1$. The estimated parameters values for all mango bars samples are presented in Table 1.

The moduli of elasticity $\left(E_{1}, E_{2}\right)$ quantify the rigidity of the material, therefore, the materials with the highest elastic moduli values are the firmest (Rodrígues-Sandoval et al., 2009). For viscoelastic solids, the stress does not completely relax but settles to an equilibrium value after a certain time. When the viscous flow of the material is exhausted the rearrangements stop and no further energy is dissipated. The elastic response persists and it is characterized by the equilibrium elastic moduli $\left(E_{e}\right)$, thus indicating the elastic nature of the material (Cespi et al., 2007). The sample $\mathrm{MP}-\mathrm{H}$ has a value of $\mathrm{E}_{\mathrm{e}}$ lower than of the other samples, meaning that almost all the energy was dissipated during relaxation, leading to a softer network at relaxation equilibrium.

As observed for $E_{1}$ and $E_{2}$ values also decreased with increasing H gellan proportion. Nussinovitch, Peleg, and Normand (1989) observed the same correlation between $\mathrm{E}_{\mathrm{e}}$ and firmness for agar and alginate gels, where softer gels presented lower $\mathrm{E}_{\mathrm{e}}$ values.

Relaxation times $\left(\lambda_{i}\right)$ and the dashpot components $\left(\eta_{i}\right)$ of the model decreased as the $\mathrm{H}$ gellan content increased. All the formulations presented a typical solid-like behaviour, as the relaxation time for the first element varied between 500 and $700 \mathrm{~s}$ (Roopa $\&$ Bhattacharya, 2014). The viscosity parameter $(\eta)$ is in accordance

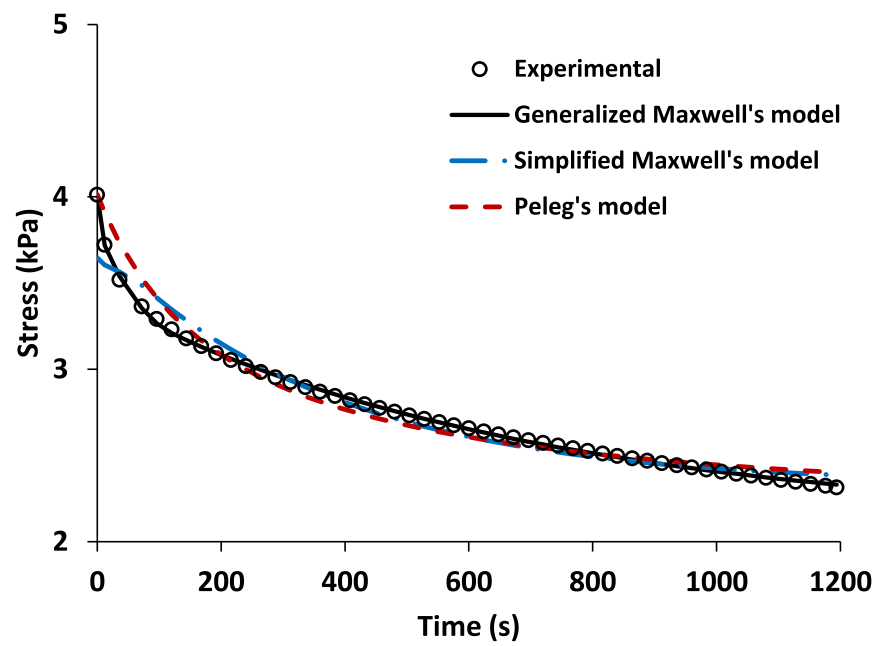

Fig. 3. (O) Experimental SR data for MP/L/H samples; the lines represent the fittings with: (-) generalized Maxwell's model with two elements; ( - ') simplified Maxwell's model and (- - -) Peleg's model.

with the moduli and relaxation times values. Samples with higher content of L gellan have a stronger network revealing higher viscosity and relaxation times.

The trend of all relaxation parameters obtained for the generalized Maxwell model indicates that the variation of the $\mathrm{L} / \mathrm{H}$ ratio affects significantly the texture of the mango bars. Different textures, from firm, with high relaxation times (composed mainly by L gellan), to soft with lower relaxation times (composed mainly by $\mathrm{H}$ gellan) were produced.

\subsection{Texture Profile Analysis}

Fig. 4 summarizes the TPA parameters, obtained upon compression of $60 \%$ of the initial sample height, as affected by the different ratios of $\mathrm{L} / \mathrm{H}$ gellan. Sample MP-L exhibited a similar hardness value to that of the samples MP-L/H75/25 and MP-L/H50/ 50 (Fig. 4a). As the H gellan content increased, a marked decrease of the hardness value was noticed for samples MP-L/H25/75 and MP$\mathrm{H}$. It is known that L gellan forms harder and more brittle gels than $\mathrm{H}$ gellan, either in simple or complex mixtures (Philips \& Williams, 2009). Consequently, a maximum value of hardness could be expected for the sample MP-L, which was not observed. This behaviour may indicate that the addition of $\mathrm{H}$ gellan up to $50 \%$ of the overall gellan concentration is not sufficient to affect substantially the firmness conferred by the L gellan to the overall MP/gellan structure. However, the overall texture of the mango bars is significant changed when $\mathrm{H}$ gellan increases, i.e., samples MP-L/H25/ 75 and MP-H have smaller values of hardness.

The springiness increased with increasing $\mathrm{H}$ gellan content, with a maximum (around 0.9) observed for the MP-L/H25/75 sample (Fig. 4b). This means that the later formulation enables the production of mango bars with the higher elastic recovery. The value of the cohesiveness (Fig. 4c) is quite similar for the formulations MP-L and MP-L/H75/25, presenting a substantial increase as the $\mathrm{H}$ acyl content increased, with a maximum for MP-H sample (0.6). Cohesiveness is related to how well the product withstands compression, so that, if a hard product maintains its internal structure without failures when subjected to compression, it would also present a high cohesiveness. In this work a decrease of cohesiveness with increasing the bars hardness is observed. This fact may be related to the observed samples fracture in the first compression, which was pronounced in the firmer samples, with higher L gellan content. The samples containing mostly $\mathrm{H}$ gellan, withstood the 
Table 1

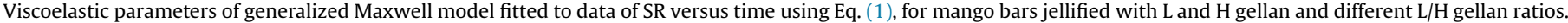

\begin{tabular}{|c|c|c|c|c|c|c|c|c|c|}
\hline Formulations & $\mathrm{E}_{1}(\mathrm{kPa})$ & $\mathrm{E}_{2}(\mathrm{kPa})$ & $\mathrm{E}_{\mathrm{e}}(\mathrm{kPa})$ & $\lambda_{1}(\mathrm{~s})$ & $\lambda_{2}(\mathrm{~s})$ & $\eta_{1}\left(\times 10^{3}\right.$ Pa s $)$ & $\eta_{2}\left(\times 10^{3} \mathrm{~Pa} \mathrm{~s}\right)$ & $\mathrm{R}^{2}$ & $\operatorname{AAD}(\%)$ \\
\hline MP-L & $13.2 \pm 0.8^{a}$ & $5.7 \pm 0.6^{\mathrm{a}}$ & $21.0 \pm 0.9^{\mathrm{a}}$ & $683.7 \pm 1.8^{\mathrm{a}}$ & $50.9 \pm 0.2^{a}$ & $9028.1 \pm 0.4^{\mathrm{a}}$ & $288.7 \pm 0.3^{\mathrm{a}}$ & 0.998 & 0.094 \\
\hline MP-L/H75/25 & $8.6 \pm 0.3^{b}$ & $4.0 \pm 0.5^{\mathrm{a}}$ & $12.2 \pm 0.5^{\mathrm{b}}$ & $625.7 \pm 1.6^{\mathrm{b}}$ & $31.7 \pm 0.1^{\mathrm{b}}$ & $5353.6 \pm 0.4^{b}$ & $127.8 \pm 0.2^{\mathrm{b}}$ & 0.999 & 0.151 \\
\hline MP-L/H50/50 & $3.6 \pm 0.3^{c}$ & $2.1 \pm 0.2^{\mathrm{b}}$ & $8.2 \pm 0.2^{c}$ & $616.2 \pm 1.4^{\mathrm{b}}$ & $27.7 \pm 0.1^{c}$ & $2231.8 \pm 0.1^{c}$ & $54.8 \pm 0.2^{\mathrm{c}}$ & 0.999 & 0.101 \\
\hline MP-L/H25/75 & $2.8 \pm 0.1^{\mathrm{d}}$ & $1.8 \pm 0.1^{\mathrm{b}}$ & $7.8 \pm 0.2^{c}$ & $600.9 \pm 1.6^{b}$ & $28.1 \pm 0.1^{\mathrm{c}}$ & $1685.4 \pm 0.1^{d}$ & $51.0 \pm 0.1^{\mathrm{c}}$ & 0.999 & 0.103 \\
\hline MP-H & $0.9 \pm 0.1^{\mathrm{e}}$ & $0.7 \pm 0.1^{c}$ & $3.6 \pm 0.1^{d}$ & $593.4 \pm 1.5^{\mathrm{b}}$ & $27.8 \pm 0.1^{\mathrm{c}}$ & $557.3 \pm 0.4^{\mathrm{e}}$ & $18.5 \pm 0.1^{\mathrm{d}}$ & 0.998 & 0.062 \\
\hline
\end{tabular}

Means of three replicates \pm SD. One-way variance analysis was performed to evaluate the statistical difference between fitting parameters.

Values in the same column followed by different superscript letters differ significantly $(\mathrm{p}<0.05)$.

first compression with fewer changes in their softer structure, leading to higher values of cohesiveness.

The TPA results demonstrate that the MP-L/H mixtures studied may be divided into two distinct groups: MP-L, MP-L/H75/25 and
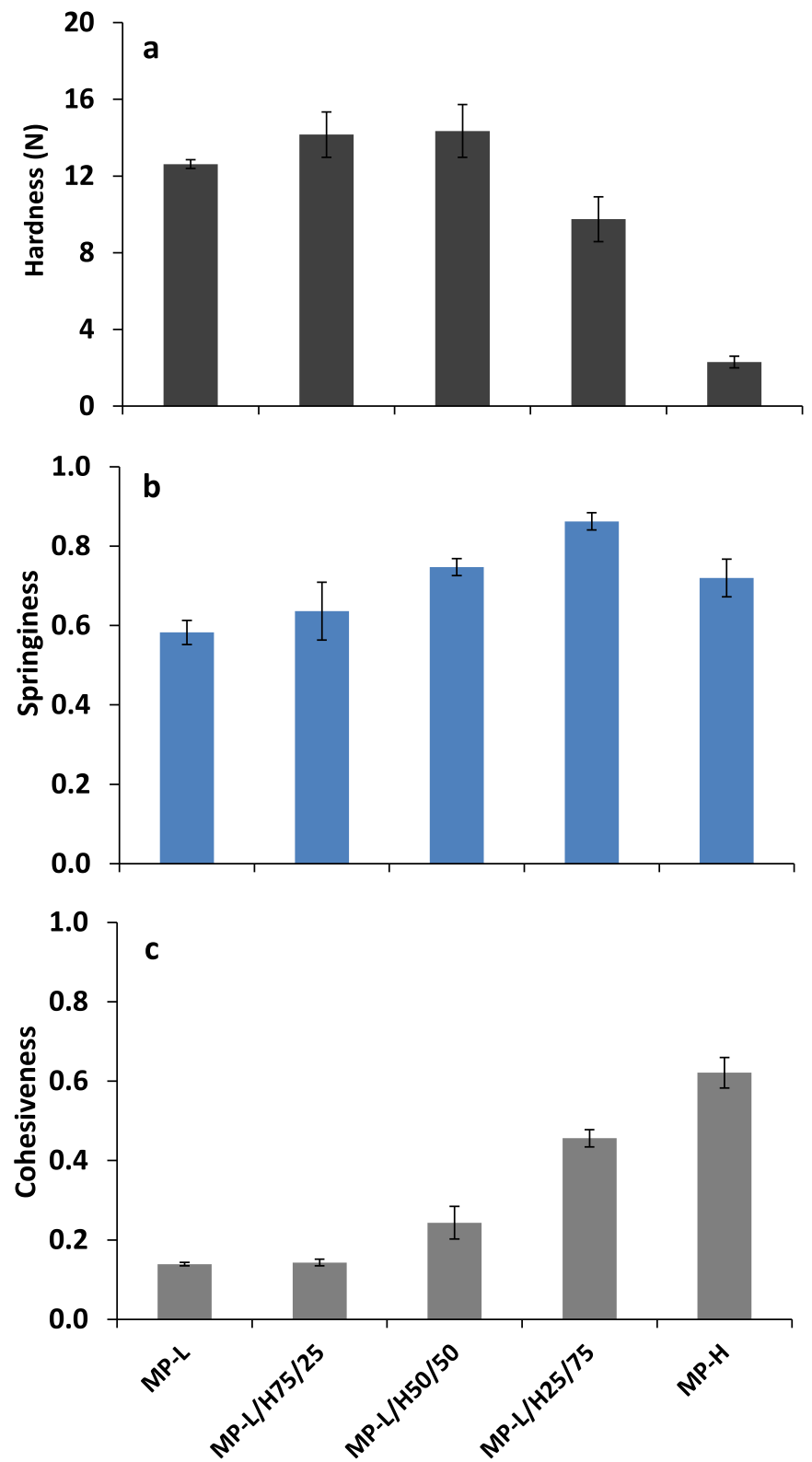

Mango bars formulations

Fig. 4. TPA parameters of $\mathrm{MP} / \mathrm{L} / \mathrm{H}$ samples: (a) hardness, (b) springiness and (c) cohesiveness.
MP-L/H50/50 samples, which are significantly harder, with lower cohesiveness and springiness than the samples MP-L/H25/75 and MP-H.

\subsection{Cryo-SEM observations}

Figs. 5 and 6 show images of the samples MP-L, MP-L/H50/50, MP-H and MP, at lower and higher magnification, respectively. The microstructure of the samples consists of a complex network made of gellan molecules together with the insoluble and soluble fibres from the MP, holding water inside. The interaction between MP constituents and $\mathrm{L} / \mathrm{H}$ blends resulted on different average pore size after water sublimation. The sample MP-L shows a continuous and dense network (Fig. 5a). By the contrary, the sample MP-H (Fig. 5c) presents a network with much higher average pore size. Sample MP-L/H50/50 shows intermediate properties, consisting on a porous structure with an average pore size lower than MP-H sample (Fig. 5b). This behaviour may be seen more clearly on CryoSEM images with higher magnifications (Fig. 6). Samples MP-L, MP-L/H75/25 and MP-L/H50/50 displayed a denser structure with pores in the range between 0.1 and $0.5 \mu \mathrm{m}$ (Fig. $6 \mathrm{a}-\mathrm{c}$ ), while the samples MP-L/H25/75 and MP-H show larger pores with thin strings (Fig. $6 \mathrm{~d}$ and e). In addition, MP-H samples display a porous structure similar to MP, with pore sizes up to $10 \mu \mathrm{m}$ (Fig. 6f).

Beyond pore size, differences in homogeneity are observed. MP displays a more homogeneous microstructure (Fig. 5d). When gellan is added, independently of the $\mathrm{L} / \mathrm{H}$ ratio, a heterogeneous structure is formed, showing different regions with small and large pores coexisting in the matrix. This fact may be related to different local chemical composition (e.g. pH, ionic strength, specific cations) that can influence the gel formation and structure. In conditions where there are enough cations and a pH value near the isoelectric point, the electrostatic repulsions are suppressed, allowing an extended aggregation of the helices, originating a more compact structure (Turgeon, Beaulieu, Schmitt, \& Sanchez, 2003). A similar behaviour was observed by Kiani, Mousav, Razavi, and Morris (2010) who studied the effect of gellan alone and in combination with high-methoxl pectin on the structure of yogurt-based drink. The authors confirmed that the structure becomes less homogeneous with the incorporation of gellan and high-methoxy pectin to the yogurt drink.

The microstructure characteristics observed by Cryo-SEM may be related to the texture parameters shown in the previous section. The denser microstructure conferred by higher L gellan content enables a higher resistance to deformation, with greater hardness. As the $\mathrm{H}$ gellan content increased, the pore size of the structure is greater, conferring less resistance to the applied deformation and, simultaneously, a higher elastic recovery as shown by the springiness values.

\subsection{Multivariate analysis of mango bars physical parameters}

To obtain an overview about the effect of $\mathrm{L} / \mathrm{H}$ gellan ratios on the textural properties of fresh fruit mango bars, a study of the 

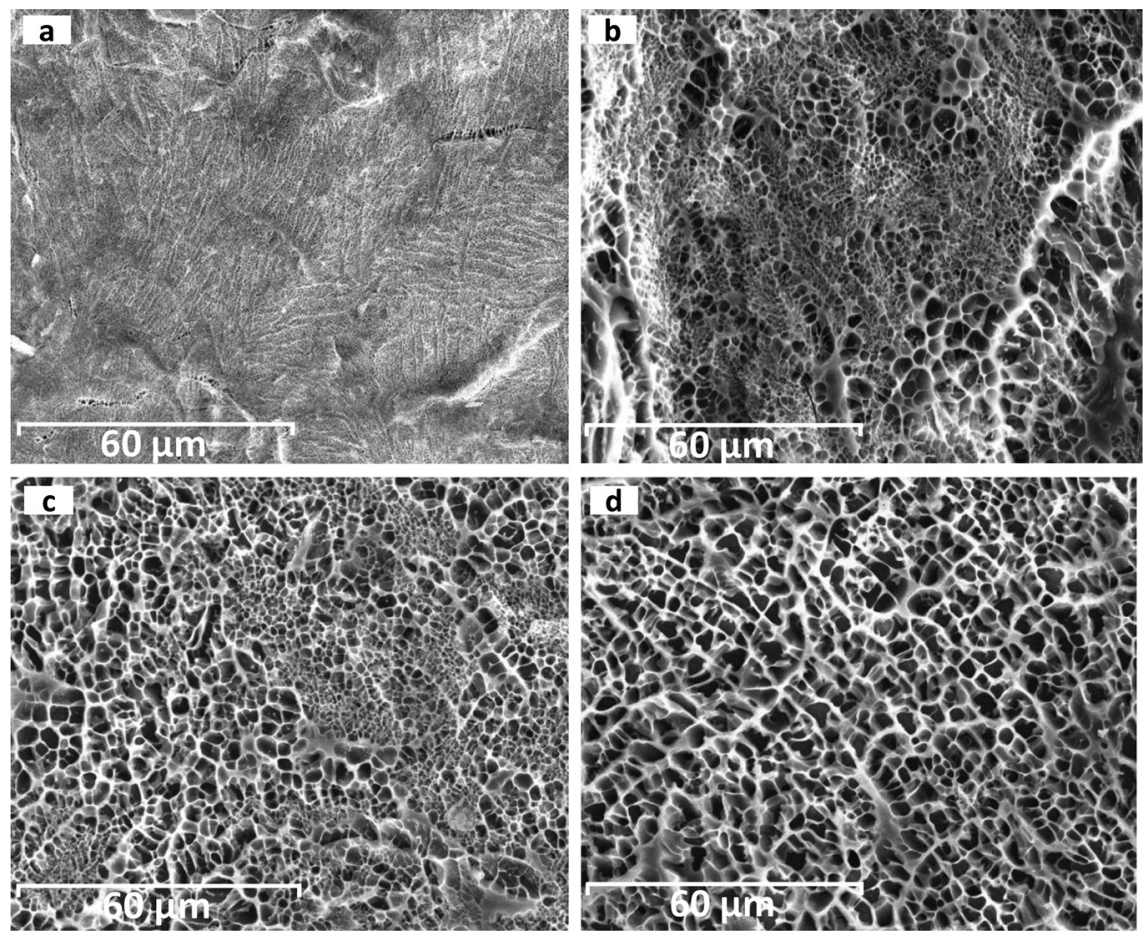

Fig. 5. CryoSEM images of MP/L/H samples at lower magnification: (a) MP-L, (b) MP-L/H50/50, (c) MP-H, (d) MP.

multivariate data was performed. PCA was conducted with respect to the mean values from TPA and SR parameters. The two principal components (PC1 and PC2) accounted for $95.5 \%$ of the total variance, (Fig. 7). PC1 explained $84.28 \%$ of the total variance with the majority of the stress-relaxation variables $\left(\lambda_{\mathrm{I}}\right.$, $\left.\mathrm{E}_{\mathrm{i}}, \eta_{\mathrm{i}}\right)$ and hardness, grouped on the positive side of $\mathrm{X}$-axis indicating high correlation with more firm samples composed of higher levels of low acyl gellan (MP-L and MP-L/H75/25). The component PC2, correlated to springiness and cohesiveness, separates the bars with only one type on gellan from those produced by $\mathrm{L} / \mathrm{H}$ blends.

\subsection{Sensory evaluation}

The preference distribution for all five mango bar formulations is presented in Fig. 8. The sample MP-L/H25/75 was significantly preferred over the others ( $\mathrm{p}<0.05$ ), with $43 \%$ of the panellists ranking it as having the most preferred texture (rank - 5). The sample MP-H was found to be the least preferred $(\mathrm{p}<0.05)$, more than $50 \%$ of the panellists did not appreciate it. This was justified, by almost $40 \%$ of the panellists, by its high adhesiveness and soft texture. No significant differences between the samples MP-L, MP$\mathrm{L} / \mathrm{H} 75 / 25$ and $\mathrm{MP}-\mathrm{L} / \mathrm{H} 50 / 50$ were observed. The preferred
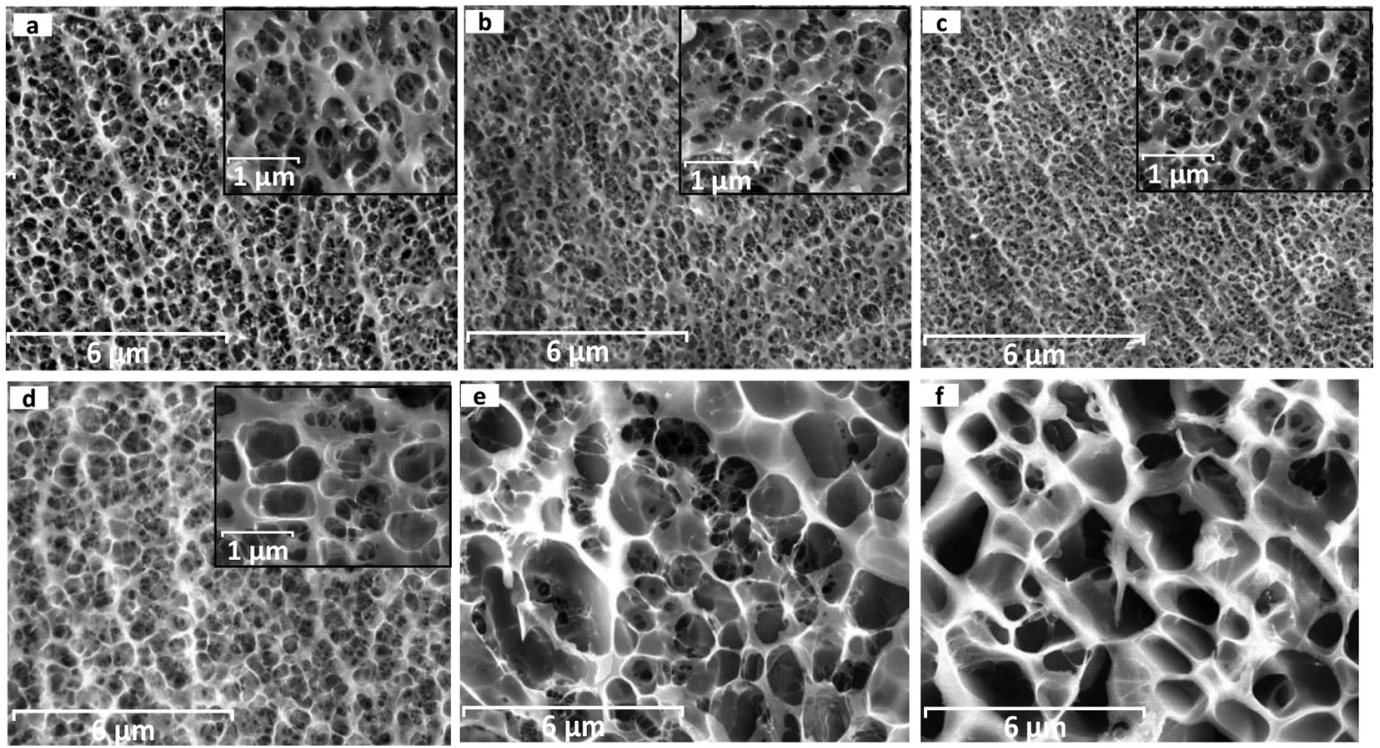

Fig. 6. CryoSEM images of MP/L/H samples at higher magnification: (a) MP-L, (b) MP-L/H75/25, (c) MP-L/H50/50, (d) MP-L/H25/75, (e) MP-H, (f) MP. 

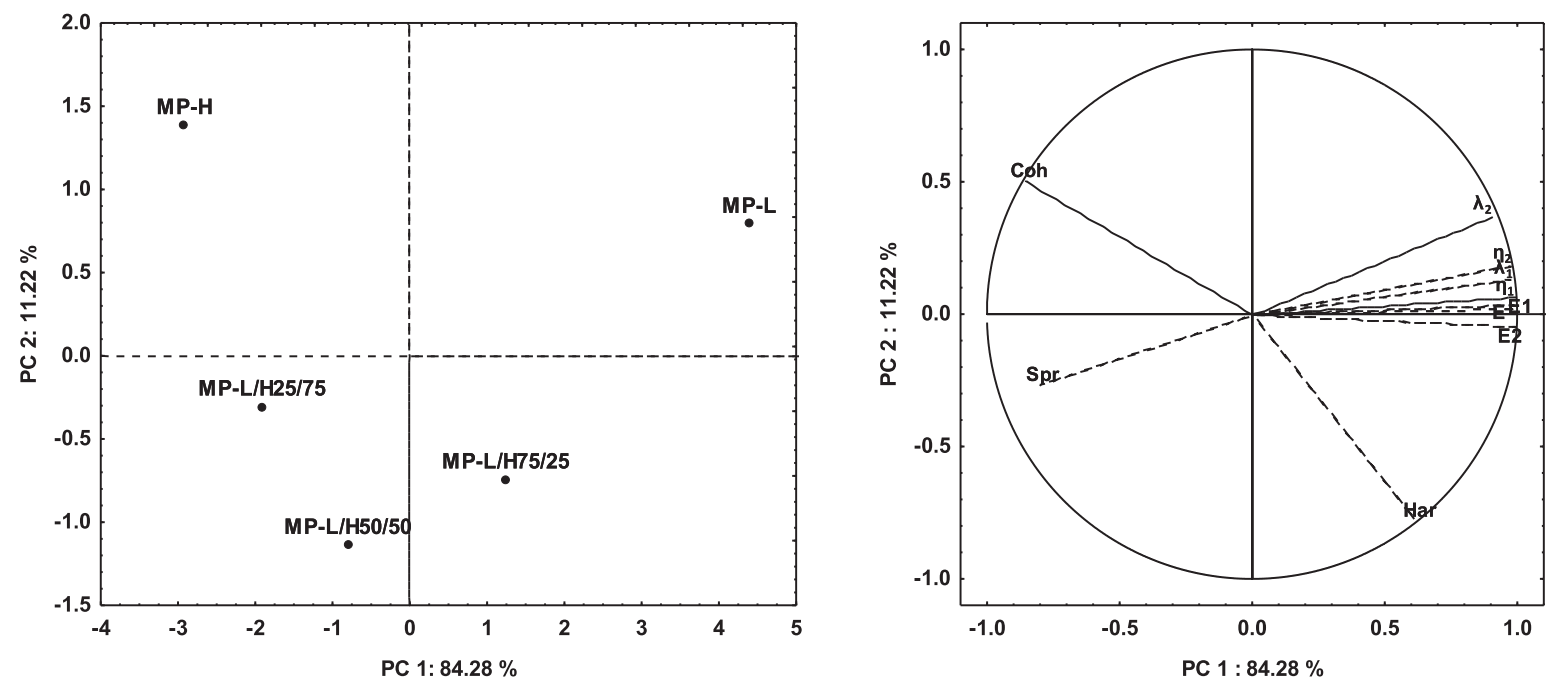

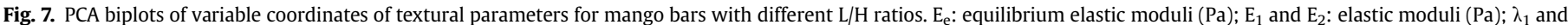
$\lambda_{2}$ : relaxation times (s); $\eta_{1}$ and $\eta_{2}$ : Viscosity (Pa s); Har: hardness (N); Spr: springiness; Coh: cohesiveness.

formulation, MP-L/H25/75, has been selected by the panellists due to more pleasant texture perception.

Considering the preferred formulation, MP-L/H25/75, it can be concluded that the low proportion of $\mathrm{L}$ gellan might be enough to impart the suitable firmness to the product, while $\mathrm{H}$ gellan, responsible for softness, imparts a well-balanced texture to the mango bar.

\section{Conclusions}

Fruit bars produced with MP jellified with gellan gum at an overall concentration of $1 \mathrm{~g} / 100 \mathrm{~g}$ varying the $\mathrm{L} / \mathrm{H}$ ratio were characterised in terms of texture, microstructure and sensory acceptance. SR and TPA tests enabled to group mango bars into two different texture profiles: (i) bars presenting higher hardness (only L gellan and $\mathrm{L} / \mathrm{H}$ ratios of $50 / 50$ and $75 / 25$ ) and (ii) bars having a softer and more cohesive structure with higher elastic recovery (only $\mathrm{H}$ gellan and $\mathrm{L} / \mathrm{H}$ at the ratio of 25/75). The texture characteristics show a strong direct relationship with the microstructure results observed by Cryo-SEM. While mango bars with higher hardness have shown a denser network with lower pore size, softer bars presented higher

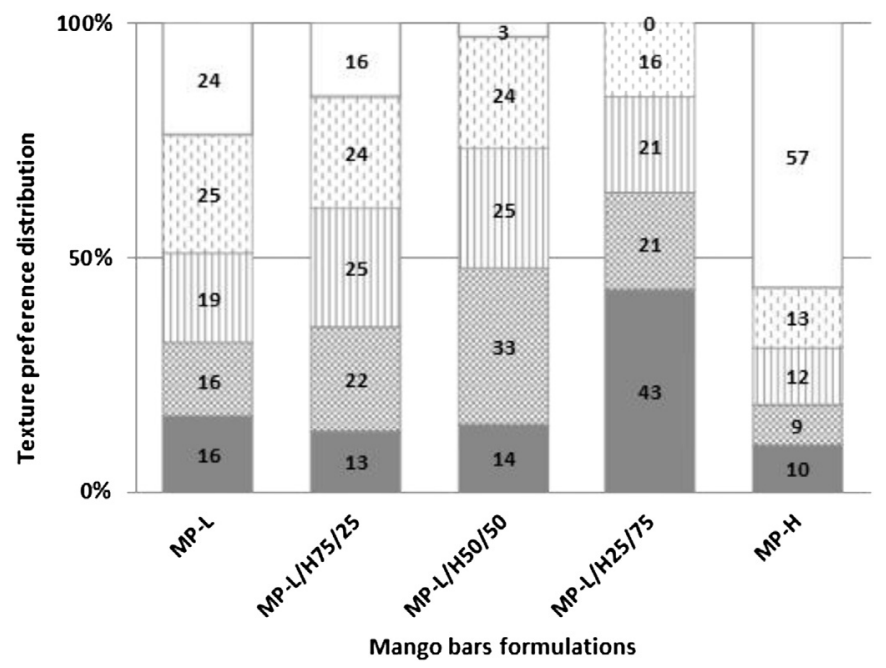

Fig. 8. Texture preference distributions for mango bars formulations at different $\mathrm{L} / \mathrm{H}$ ratios. Symbols: 1 ( $\square$ )-least; 2 (医)-slightly; 3 (四)-neither like nor dislike; 4 (四)-moderately and $5(\square)$ - most preferred springiness and larger pores. The preferred texture identified by Preference-Ranking test was the one prepared with an $\mathrm{L} / \mathrm{H}$ ratio of 25/75. Further studies will be carried out with the selected formulation in what concerns product packaging and conservation.

\section{Acknowledgements}

The authors acknowledge Fundação para a Ciência e a Tecnologia for the research grant SFRH/BD/64341/2009, for the funding projects PTDC/AGR-ALI/114706/2009 and PEst-OE/AGR/UI0245/ 2014 and CP Kelco Company for providing the gellan gum.

\section{References}

Andrés, S. C., Zaritzky, N. E., \& Califano, A. N. (2008). Stress relaxation characteristics of low-fat chicken sausages made in Argentina. Meat Science, 79, 589-594.

Bajaj, I., \& Singhal, R. (2007). Gellan gum for reducing oil uptake in sev, a legume based product during deep-fat frying. Food Chemistry, 45, 341-354.

Banerjee, S., \& Bhattacharya, S. (2011). Multi-component gels: compressive textural attributes, opacity and syneresis of gellan, agar and their mixtures. Journal of Food Engineering, 102, 287-292.

Banerjee, S., Ravi, R., \& Bhattacharya, S. (2013). Textural characterisation of gellan gum and agar based fabricated gels with carrot juice. LWT - Food Science and Technology, 53, 255-261.

Bayarri, S., Costell, E., \& Duran, L. (2002). Influence of low sucrose concentration on the compression resistance of gellan gum gels. Food Hydrocolloids, 16, 593-597.

Bellido, G. G., \& Hatcher, D. W. (2009). Asian noodles: revisiting Peleg's analysis for presenting stress relaxation data in soft solid foods. Journal of Food Engineering, 92, 29-36.

Bicas, J. L., Molina, J., Dionisio, A. P., Barros, F. F. C., Wagner, R., Maróstica, M. R., Jr. et al. (2011). Volatile constituents of exotic fruits from Brasil. Food Research International, 44, 1843-1855.

Campus, M., Addis, M. F., Cappuccinelli, R., Porcu, M. C., Pretti, L., Tedde, V., et al. (2010). Stress relaxation behaviour and structural changes of muscle tissues from Gilthead Sea Bream (Sparus aurata L.) following high pressure treatment. Journal of Food Engineering, 96, 192-198.

Cespi, M., Bonacucina, G., Misici-Falzi, M., Golzi, R., Boltri, L., \& Palmieri, G. F. (2007). Stress relaxation test for the characterization of the viscoelasticity of pellets. European Journal of Pharmaceutics and Biopharmaceutics, 67, 476-484.

Chandrasekaran, R., \& Radha, A. (1995). Molecular architectures and functional properties of gellan gum and related polysaccharides. Trends in Food Science \& Technology, 6, 143-148.

Chen, L., \& Opara, U. L. (2013). Texture measurement approaches in fresh and processed foods - a review. Food Research International, 51, 823-835.

Danalache, F., Mata, P., Moldão-Martins, M., \& Alves, V. D. (2015). Novel mango bars using gellan gum as gelling agent: rheological and microstructural studies. LWT - Food Science and Technology, 62(1), 576-583. http://dx.doi.org/10.1016 | j.lwt.2014.09.037.

Djantou, E. B., Mbofung, C. M. F., Scher, J., Phambu, N., \& Morael, J. D. (2011). Alternation drying and grinding (ADG) technique: a novel approach for producing ripe mango powder. LWT - Food Science and Technology, 44, 1585-1590. 
García, M. C., Alfaro, M. C., Calero, N., \& Muňoz, J. (2011). Influence of gellan gum concentration on the dynamic viscoelasticity and transient flow of fluid gels. Biochemical Engineering Journal, 55, 73-81.

Gorinstein, S., Zemser, M., Haruenkit, R., Chuthakorn, R., Grauer, F., Martin Belloso, O., et al. (1999). Comparative content of total polyphenols and dietary fiber in tropical fruits and persimmon. Journal of Nutritional Biochemistry, 10, $367-371$.

Kaletunc, G., Normand, M. D., Nussinovitch, A., \& Peleg, M. (1991). Determination of elasticity of gels by successive compression-decompression cycles. Food $\mathrm{Hy}$ drocolloids, 5, 237-247.

Kiani, H., Mousav, M. E., Razavi, H., \& Morris, E. R. (2010). Effect of gellan, alone and in combination with high-methoxy pectin, on the structure and stability of doogh, a yogurt-based Iranian drink. Food Hydrocolloids, 24, 744-754.

Lau, M. H., Tang, J., \& Paulson, A. T. (2000). Texture profile and turbidity of gellan/ gelatin mixed gels. Food Research International, 33, 665-761.

Ledeker, C. N., Suwonsichon, S., Chamber, D. H., \& Adhikari, K. (2014). Comparison of sensory attributes in fresh mangoes and heat-treated mango purées prepared from Thai cultivars. LWT - Food Science and Technology, 56, 138-144.

Liu, F., Li, R., Wang, Y., Bi, X., \& Liao, X. (2014). Effects of high hydrostatic pressure and high-temperature short-time on mango nectars: changes in microorganisms, acid invertase, 5-hydroxymethylfurfural, sugars, viscosity, and cloud. Innovative Food Science and Emerging Technologies, 22, 22-30.

Mancini, F., \& McHugh, T. H. (2000). Fruit-alginate interactions in novel restructured products. Nahrung, 44(3), 152-157.

Mancini, M., Moresi, M., \& Rancini, R. (1999). Mechanical properties of alginate gels: empirical characterization. Journal of Food Engineering, 39, 369-378.

Mandala, I. J., Palogou, E. D., \& Kostaropoulos, A. E. (2007). Influence of preparation and storage conditions on texture of xanthan-starch mixtures. Journal of Food Engineering, 53, 27-38.

Mao, R., Tang, J., \& Swanson, B. G. (2000). Texture properties of high and low acyl mixed gellan gels. Carbohydrate Polymers, 41, 331-338.

Meilgaard, M., Civille, G. V., \& Carr, B. T. (1999). Sensory evaluation techniques. In Affective tests: Consumer tests and in-house panel acceptance tests (pp. 231-263).

Morris, E. R., Nishinari, K., \& Rinaudo, M. (2012). Gelation of gellan - a review. Food Hydrocolloids, 28, 373-411.

Noda, S., Funami, T., Nakauma, M., Asai, I., Takahashi, R., Al-Assaf, S., et al. (2008). Molecular structure of gellan gum imaged with atomic force microscopy in relation to the rheological behaviour in aqueous systems. 1. Gellan gum with various acyl contents in the presence and absence of potassium. Food Hydrocolloids, 22, 1148-1159.

Nussinovitch, A., Peleg, M., \& Normand, M. D. (1989). A modified Maxwell and a non-exponential model for characterization of the stress relaxation of agar and alginate gels. Journal of Food Science, 54(4), 1013-1016.

Ortega, D., \& Sanderson, G. R. (1994). Dessert gels prepared from alginate and gellan gum. In Gums and stabilizers for the food industry (Vol. 7, pp. 385-392). Oxford IRL Press/Oxford University Press.

Pereira, P. A. P., Rios de Sousa, V., Teixeira, T. R., Queiroz, F., Borges, V. S., \& Carneiro, J. S. (2013). Rheological behaviour of functional sugar-free guava preserves: effect of the addition of salts. Food Hydrocolloids, 31, 404-412.

Philips, G. O., \& Williams, P. A. (2009). Handbook of hydrocolloids (2st ed.) England, (Chapter 9).

Rodrígues-Sandoval, E., Fernandez-Quintero, A., \& Cuvelier, G. (2009). Stress relaxation of reconstituted cassava dough. LWT - Food Science and Technology, 42, 202-206.
Roopa, B. S., \& Bhattacharya, S. (2014). Mango gels: characterization by smalldeformation stress relaxation method. Journal of Food Engineering, 131, $38-43$.

Saha, D., \& Bhattacharya, S. (2010). Characteristics of gellan gum based food gels. Journal of Texture Studies. http://dx.doi.org/10.1111/j.1745-4603.2010.00236.x.

Schieber, A., Ullrich, W., \& Carle, R. (2000). Characterisation of polyphenols in mango purée concentrate by HPLC with diode array and mass spectrometric detection. Innovative Food Science and Technologies, 1, 161-166.

Sogi, D. S., Siddiq, M., \& Dolan, K. D. (2015). Total phenolics, carotenoids and antioxidant properties of Tommy Atkin mango cubes as affected by drying techniques. LWT - Food Science and Technology, 62(1), 564-568. http://dx.doi.org/ 10.1016/j.lwt.2014.04.015.

Sriamornsak, P. Thirawong, N., Cheewatanakornkool, K, Burapapadh, K, \& SaeNgow, W. (2008). Cryo-Scanning Electron Microscopy (Cryo-SEM) as a tool for studying the ultrastructure during bead formation by ionotropic gelation of calcium pectinate. International Journal of Pharmaceutics, 352, 115-122.

Sriwimon, W., \& Boonsupthip, W. (2011). Utilization of partially ripe mangoes for freezing preservation by impregnation of mango juice and sugars. LWT - Food Science and Technology, 44, 375-383.

Sworn, G. (2000). Gellan gum. In G. O. Philips, \& P. A. Williams (Eds.), Handbook of hydrocolloid (pp. 117-134). New York: Woodhead Publishing Ltd.

Sworn, G., \& Kasapis, S. (1999). Molecular origins of the rheology of high sugar gellan systems. Progress in Colloid and Polymer Science, 114, 116-122.

Tang, J., Tung, M. A., \& Zeng, Y. (1998). Characterisation of gellan gels using stress relaxation. Journal of Food Engineering, 38, 279-295.

Turgeon, S. L., Beaulieu, M., Schmitt, C., \& Sanchez, C. (2003). Protein-polysaccharide interactions: phase-ordering kinetics, thermodynamic and structural aspects. Current Opinion in Colloid and Interface Science, 8, $401-414$.

Yamamoto, F. \& Cunha, R. L. (2007). Acid gelation of gellan: effect of final pH and heat treatment conditions. Carbohydrate Polymers, 68, 517-527.

Yildiz, O., Yurt, B., Baştürk, A., Toker, O. M., Yilmaz, M. T., Karaman, S., et al. (2013). Pasting properties, texture profile and stress-relaxation behavior of wheat starch/dietary fiber systems. Food Research International, 53, $278-290$.

Zhang, J., Daubert, C. R., \& Foegeding, E. (2005). Characterization of polyacrylamide gels as an elastic model for food gels. Rheologica Acta, 44, 622-630.

\section{Abbreviations}

MP: mango puree

$H$ : high acyl gellan

$L$ : low acyl gellan

$M P-L$ : mango puree with only low acyl gellan

$M P-L / H 75 / 25$ : mango puree with a low acyl/high acyl gellan ratio of 75/25

MP-L/H50/50: mango puree with a low acyl/high acyl gellan ratio of 50/50

MP-L/H25/75: mango puree with a low acyl/high acyl gellan ratio of $75 / 25$

$M P-H$ : mango puree with only high acyl gellan

ANOVA: Analysis of Variance

TPA: Texture Profile Analysis

$S R$ : Stress Relaxation

PCA: Principal Component Analysis

Cryo-SEM: Cryo-Scanning Electron Microscopy 